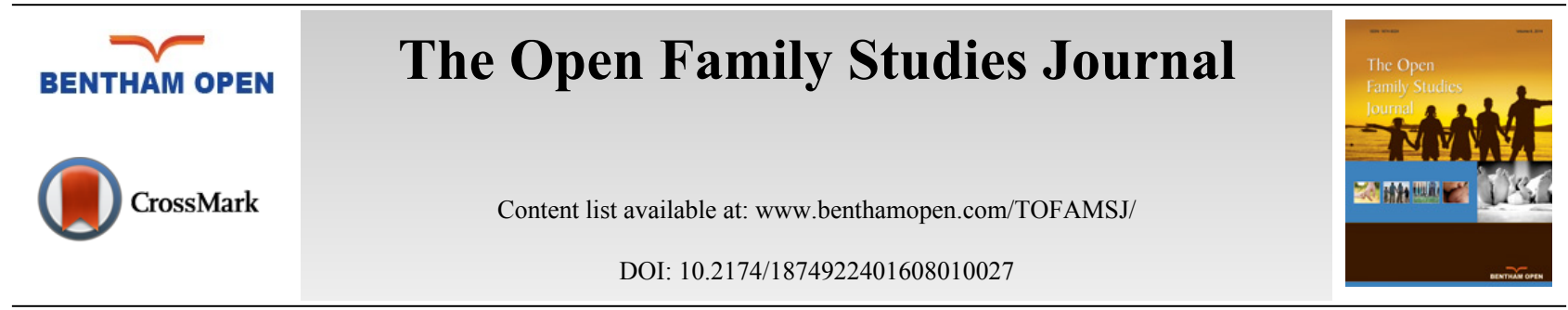

RESEARCH ARTICLE

\title{
Mother-To-Infant Bonding Disorder, but not Depression, 5 days After Delivery is a Risk Factor For Neonate Emotional Abuse: A Study in Japanese Mothers of 1-Month Olds
}

\author{
Yukiko Ohashi $^{1,2}$, Kyoko Sakanashi ${ }^{3}$, Tomoko Tanaka ${ }^{4}$ and Toshinori Kitamura, ${ }^{1,5 *}$ \\ ${ }^{1}$ Kitamura Institute of Mental Health Tokyo, Tokyo, Japan \\ ${ }^{2}$ Department of Nursing, Faculty of Health Science Technology, Bunkyo Gakuin University, Japan \\ ${ }^{3}$ Department of Women's Health/Mother-Child Nursing, Faculty of Life Science, Kumamoto University, Kumamoto, \\ Japan \\ ${ }^{4}$ Aso Health Center, Kumamoto Prefecture, Aso, Japan \\ ${ }^{5}$ Department of Psychiatry, Graduate School of Medicine, Nagoya University, Nagoya, Japan
}

Received: September 01, 2016

Revised: November 03, 2016

Accepted: November 05, 2016

\begin{abstract}
:
Background:

Despite its clinical and public policy-making importance, neonatal abuse has been only minimally studied.
\end{abstract}

Purpose:

To identify predictors of mothers' emotional abuse towards their infants at 1 month after childbirth.

Methods:

We studied a cohort of 252 women at three time points: late pregnancy and 5 days and 1 month after childbirth. At each time point, the women were administered a set of questionnaires about their depression (Edinburgh Postnatal Depression Scale), bonding towards the foetus or neonate (Maternal Antenatal Attachment Scale and Postnatal Bonding Questionnaire, respectively), and, at 1 month after childbirth, emotional abuse (Conflict Tactic Scale).

Results:

Structural equation modeling (SEM) analysis revealed that neonatal emotional abuse was predicted by bonding difficulties at 5 days after childbirth but not by depression at that time point.

\section{Conclusion:}

Assessment for maternal bonding problems in the early post-natal period should be routinely performed by perinatal health professionals.

Keywords: Bonding Disorder, Depression, Neonatal Abuse, Maternal Response to the Pregnancy, SEM.

\section{INTRODUCTION}

Child abuse is an important psychological, educational, and legal issue worldwide. There is ample evidence suggesting that past experiences of neglect and child physical, psychological, and sexual abuse increase the risk of a

\footnotetext{
* Address correspondence to this author at the Kitamura Institute of Mental Health Tokyo, Flat A, Riverlandhouse Tomigaya, 2-26-3, Tomigaya, Shibuya, Tokyo, Japan; Tel: 81-3-5738-8371; E-mail: kitamura@institute-of-mental-health.jp
} 
range of psychiatric disorders, substance use disorders, suicide attempts, sexually transmitted infections, and risky sexual behaviour in later life [1]. The annual incidence of infant abuse reported to the National Child Abuse and Neglect Data System in the United States was 23.2 cases per 1,000 [2]. In 39\% of cases the infants were less than 1 month old, and about $80 \%$ of instances occurred within 1 week after childbirth. More than half of the reported cases were of neglect. Hence, neonates and infants are at particular risk of child abuse. In Japan, however, despite the clinical importance of infant and neonatal abuse, virtually no empirical studies have been conducted on abuse of infants aged less than 1 month.

Exploration of the factors affecting the risk of abusive parenting is a prerequisite for implementing effective preventive strategies. Previous studies revealed that psychological factors were related to abusive parenting style. Such factors include parenting stress [3, 4], undesired pregnancy [5, 6], bonding impairment [7], and parental psychopathology $[8-10]$ and personality disorders [11, 12]. There are at least three important correlates of neonatal/infant abuse, the first being maternal depression. There is ample evidence that mothers with depression are more likely to show maladaptive parenting styles [9, 13 - 27]. Maternal child abuse may be correlated with maternal depression. For example, De Bellis et al. compared caregivers of maltreated and non-maltreated children or adolescents [8]. The lifetime prevalence of maternal major depression was significantly higher when offspring were maltreated $(72 \%)$ than when they were not $(22 \%)$. In a large community study, Walsh, MacMillan, \& Jamieson reported that physical abuse had occurred in $41 \%$ of respondents with at least one parent with a history of depression, compared to only $23 \%$ of respondents with parents who were not depressed [10]. The proportion of childhood sexual abuse showed a similar trend: $18 \%$ of respondents reporting a history of parental depression were sexually abused, as opposed to $6 \%$ of respondents with no history of parental depression. In a longitudinal study of newborns followed up until age three years, Windham et al. found a correlation between maternal depression and severe child physical abuse and assault on the child's self-esteem [28]. These previous studies all indicated substantial association between the risk of child abuse and maternal depression, but all used correlational statistical analyses. Hence, it is unknown whether maternal depression leads to child abuse or vice versa, or if the two are confounded by one or more other variables. Longitudinal follow-up studies incorporating causal path models are still required.

The second important correlate of abusive parenting is bonding disorder. Mothers of newborns may experience aversive feelings in their early relationships with their infants. These include lack of affection or hatred towards the babies, impulses to harm them, or rejection or neglect [7, 29 - 31]. About a quarter of mothers referred to psychiatrists for child abuse had disorders of the mother-infant relationship [32]. When bonding disorder is severe, mothers may try to escape or to seek permanent transfer of infant care within or outside of the family. Bonding difficulty, and in particular its subscale Anger and Rejection, is associated with trait anger [33]. In a study of a Japanese community population of mothers of 3-month-olds, Kitamura, Ohashi, Kita, Haruna, \& Kubo revealed that an abusive parenting pattern was associated, albeit weakly, with maternal depression and bonding difficulty [34]. In a non-recursive structural equation model, they revealed that an abusive parenting pattern was predicted by the other two variables. However, this again was a cross-sectional study.

The third potential factor affecting abusive parenting after childbirth is unwanted pregnancy, though there is minimal empirical evidence regarding this relationship. Nevertheless, there is indirect evidence suggesting that unwanted pregnancy has an adverse effect on mothers' parenting styles. Postnatal depression is more likely in women with unintended pregnancies at both 3 and 12 months after childbirth [35]. Kokubu, Okano, \& Sugiyama reported that negative attitudes towards pregnancy predicted bonding difficulties within the 5 days after delivery in a Japanese nonclinical maternal population [36]. Hence we were interested in whether negative attitudes towards pregnancy in expectant and new mothers are associated with both bonding disorder and depression after childbirth, and whether negative attitudes towards pregnancy lead to foetal/neonatal abuse. This latter effect, if it exists, may be mediated via bonding disorder and depression after childbirth.

In this study, we longitudinally investigated a Japanese nonclinical maternal population with a focus on how emotional abuse towards infants was influenced by depression, bonding disorder, and the women's response to pregnancy. We hypothesized that negative maternal attitudes towards pregnancy would increase the risk of emotional abuse of neonates and that this increased risk would be mediated by maternal depression and bonding disorder during and after pregnancy. Furthermore, we hypothesized that maternal depression and bonding disorder at one time point in the perinatal period would predict each other at a later time point. 


\section{METHODS}

\section{Participants and Procedure}

This multi-wave study was conducted in Kumamoto Prefecture, Japan. Kumamoto, located in the middle of the island of Kyushu, Japan, has a population of about 1,873,000. Fifty-five obstetric clinics are located in the prefecture. We invited all 55 clinics to participate in the present questionnaire study, and 18 (33\%) responded to our request. The participating clinics included the university hospital, public and private hospitals $(n=12)$, and private clinics $(n=5)$. We then used an invitation leaflet to solicit pregnant women of at least 28 weeks gestation who attended one of these antenatal clinics during the entire month of November 2011. The mean (SD) gestational age of the subjects was 34.35 (3.84) weeks at the time of entry into the study. The survey was repeated postnatally at 5 days (while women were still in the hospital) and 1 month (when they attended their 1-month health check-up). At each time point, the participating women were asked to take the questionnaire home, fill it in, and return it using a prestamped envelope to the researcher (T.K.). Of 1,442 eligible women, 618, 437, and 384 returned the questionnaire at late pregnancy, 5 days after childbirth, and 1 month after childbirth, respectively. The number of women who returned the questionnaire at all three study points (entry and 5 days and 1 month after childbirth) was 252 (17.5\%); these women comprised the study population. The present study was approved by the Ethical Committee of Kumamoto University Graduate School of Life Sciences.

\section{Measures}

Neonate emotional abuse. We assessed neonatal emotional abuse using the Conflict Tactics Scale (CTS) [37]. This is a self-report measure of the frequency of different types of abusive parenting behaviours that have occurred since the most recent childbirth. The CTS Child Form R focuses specifically on the parent's psychological (emotional) and physical aggression towards the child. It consists of 19 items rated on a 7-point scale $(0=$ "never" to $6=$ "more than 20 times"). The first three items, for instance "discussed an issue calmly", rate negotiation and hence were excluded from the subsequent analyses. There are seven items concerning psychological aggression and nine related to physical abuse. In this study, we used only the psychological aggression items because our mothers' infants were only 1 month old and there were a negligibly small number of positive responses to the items tapping physical abuse (one mother reported physical abuse). The time frame of the instrument was changed from the original "last year" to "the time period since child birth". The questionnaire was translated by one of us (T.K.) after obtaining permission from the original author.

Depression. We administered the Edinburgh Postnatal Depression Scale (EPDS) [38] at all three study points. The EPDS is a 10-item questionnaire rated on a 4-point scale ( 0 to 3 ); it assesses postnatal depression and is commonly used in many perinatal settings. Higher scores indicate more severe depressive symptoms. The psychometric properties of the EPDS have been reported to be excellent [38]. A Japanese version of the EPDS is available and the reliability and validity were previously verified [39]. Because one of our aims was to consecutively track the mothers' depressive moods from the late pregnancy period to the postnatal period, we used the EPDS throughout the perinatal period.

Bonding towards the foetus. The Maternal Antenatal Attachment Scale (MAAS) [40] is a self-report measure composed of 19 statements that are intended to measure the quality and quantity of pregnant women's affective attachment towards their unborn child, both in terms of feelings and behaviour. Each statement is followed by individual response options that range, for example, from "Very pleased" to "Very sad", or "A lot of time each day" to "Not at all". Responses are scored from 1 to 5 points and thus the maximum score is 95 . Higher scores represent better bonding towards the foetus. The original MAAS was translated into Japanese by one of us (T.K.) after obtaining permission from the original author.

Bonding disorder towards the newborn baby. We used the Japanese version [41] of the Postnatal Bonding Questionnaire (PBQ) [42, 43]. The PBQ is a self-report measure of parents' attitudes and emotions towards their newborn baby. It consists of 25 items rated on a 6-point scale (0 to 5). Eight items are positively worded, and these are reverse scored. Higher scores indicate that the parent has a less positive affect towards the baby and experiences a psychological burden regarding parenting. The psychometric properties in a Japanese population have been reported [44 - 46]. For the present analyses, we used the three-factor model that was identified in our previous study [46]; the factors are Lack of Affection, Rejection and Fear, and Anger and Restrictedness. In this study the PBQ was distributed to the participants at day 5 and 1 month after childbirth.

Maternal response to the pregnancy. In the first-wave questionnaire, we asked each mother for her response to the present pregnancy when she first learnt she was pregnant $(1=$ very pleased to $5=$ very displeased $)$. A higher score indicated that the mother felt that the pregnancy was unwanted. 
Demographic and obstetric data. Demographic data included the age and parity (primipara/multipara) of each woman as well as the following complications of pregnancy: threatened labour; pregnancy hypertension; placenta previa; anomaly of the foetus; and birth outcomes, specifically planned and emergency Caesarean sections. Complications of delivery were obtained from medical records.

\section{STATISTICAL ANALYSES}

We excluded 10 participants who rated less than $80 \%$ of the study variables or $50 \%$ of the items in each measure. Missing data were substituted using multiple imputation. We first examined the means and SEs of all the variables used in this study and then correlated them. Subsequently, we created a structural equation model (SEM) to clarify the temporal relationships between the variables (Fig. 1). Here we posited that (1) depression at one time point would predict that at the next time point, (2) foetal/neonatal bonding would predict that at the next time point, (3) emotional child abuse at 1 month after childbirth would be predicted by both depression and bonding difficulty at 5 days after childbirth, and (4) the mother's response towards pregnancy would predict depression and bonding or bonding disorders during pregnancy and after childbirth. We also posited that variables at the same time point would co-vary with each other. In the later analyses, the full information maximum likelihood method was used to substitute missing data [47]. Finally, some paths were trimmed depending on the improvement of the fit index if the new model did not show a statistically significant increase in the chi-squared value [48, pp. 145-147].

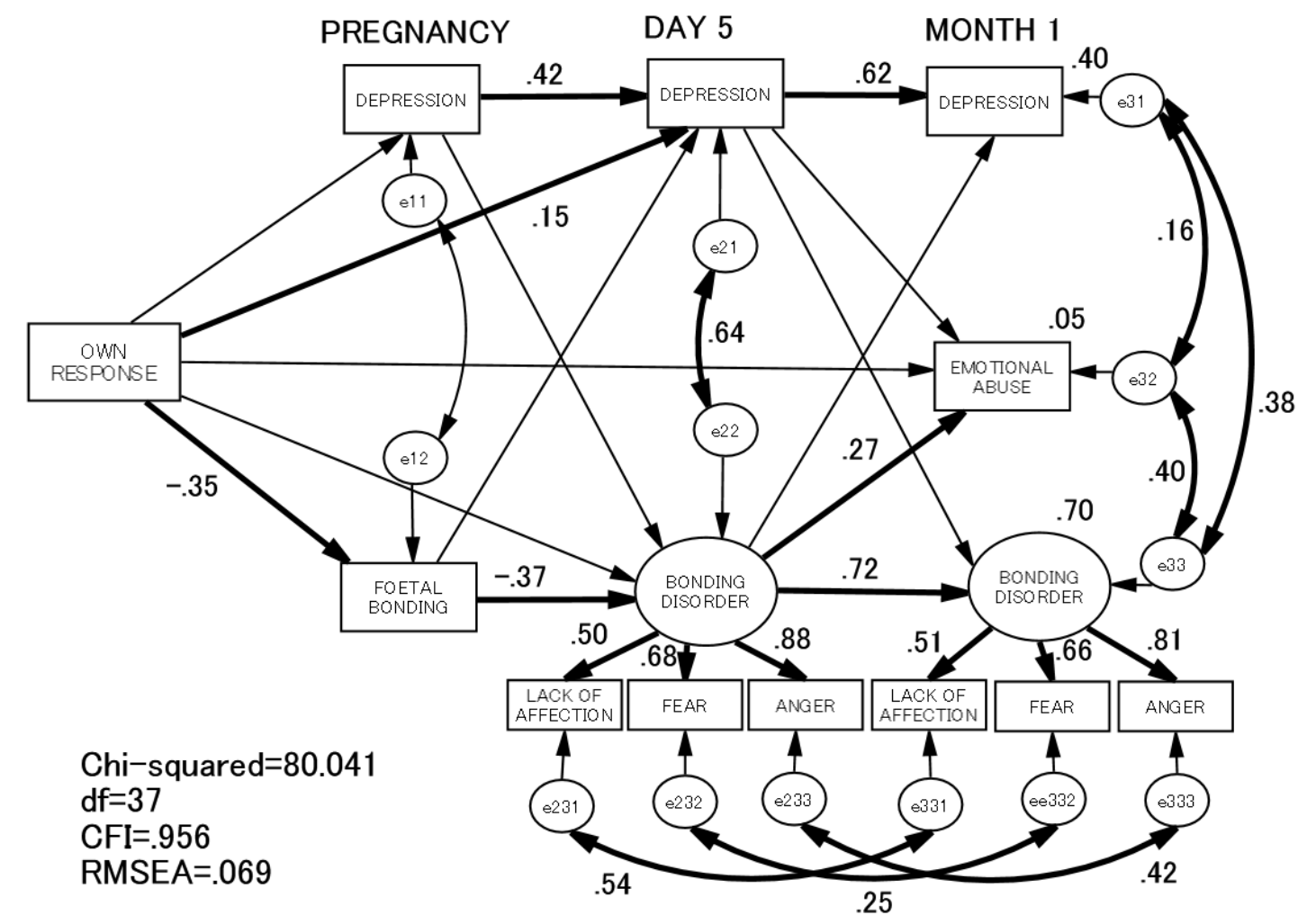

Fig. (1). Structural equation modeling of the relationships between emotional neonate abuse and other variables. Significant paths are in bold. Non-significant path coefficients are not shown. Missing values were imputed by the full information maximum likelihood method [47].

The fit of each model with the data was examined in terms of chi-squared (CMIN), comparative fit index (CFI), and root mean square error of approximation (RMSEA). According to conventional criteria, a good fit would be indicated by $\mathrm{CMIN} / d f<2, \mathrm{CFI}>0.97$, and RMSEA $<0.05$, and an acceptable fit by CMIN $/ d f<3$, CFI $>0.95$, and RMSEA $<$ 0.08 [49].

All statistical analyses were conducted using SPSS version 20.0 [IBM Japan, Tokyo, Japan] and Amos 20.0 [IBM Japan]. 


\section{RESULTS}

\section{Demographics}

The mean (SD) age of the participants was 30.19 (4.66) years. Ninety-nine percent of them were married. There were 116 first-time mothers $(50 \%)$ and 118 who were multiparous (eight did not specify). Pregnancy complication(s) were reported by $45 \%$ of the women, including pregnancy hypertension, placenta previa, and threatened premature labour. A little more than a quarter $(29 \%)$ of the participants had delivery complications, including premature rupture of the membranes and cephalopelvic disproportion. Overall, these findings regarding attributes did not differ from those in a community population of mothers in Japan [50]. Most of the characteristics of this population, namely mother's age, number of children, marriage history, child gender, pregnancy complications, and past disease history, were not statistically significantly different from those of the women not included in the study. However, the included mothers experienced more delivery complications $\left(X^{2}=5.44, p<0.05\right)$ (Table $\left.\mathbf{1}\right)$.

Table 1. Demographic characteristics of included and excluded mothers.

\begin{tabular}{|c|c|c|c|c|c|c|}
\hline \multirow[b]{2}{*}{ Age (years) } & \multicolumn{2}{|c|}{$\begin{array}{c}\text { Included mothers } \\
(N=232-242) \\
\text { Mean }(S D) \\
\end{array}$} & \multicolumn{2}{|c|}{$\begin{array}{c}\text { Excluded mothers } \\
(N=1144-1211) \\
\text { Mean }(S D)\end{array}$} & \multirow{2}{*}{$\begin{array}{c}t \\
1.35 \\
\end{array}$} & \multirow{2}{*}{$\begin{array}{c}\boldsymbol{p} \\
\text { n.s. }\end{array}$} \\
\hline & 30.19 & $(4.66)$ & 29.70 & $(5.13)$ & & \\
\hline Number of children & 0.68 & $(0.83)$ & 0.75 & $(0.90)$ & -1.06 & n.s. \\
\hline \multirow[t]{2}{*}{ Partner's age (years) } & 32.3 & $(6.0)$ & 31.9 & $(5.9)$ & 0.72 & n.s. \\
\hline & \multicolumn{2}{|c|}{$N$} & \multicolumn{2}{|c|}{$N$} & $\chi^{2}$ & $p$ \\
\hline Pregnancy complications, and past disease history (yes: no) & \multicolumn{2}{|c|}{ 111: 122} & \multicolumn{2}{|c|}{ 519: 692} & 1.82 & n.s. \\
\hline Delivery complications (yes: no) & \multicolumn{2}{|c|}{$68: 164$} & \multicolumn{2}{|c|}{ 254: 890} & 5.44 & 0.02 \\
\hline Marriage history (married: unmarried: single) & \multicolumn{2}{|c|}{ 236: $0: 4$} & \multicolumn{2}{|c|}{$374: 2: 5$} & 1.09 & n.s. \\
\hline Child gender (boy: girl: twin or more) & \multicolumn{2}{|c|}{ 116: $112: 4$} & \multicolumn{2}{|c|}{ 578: 543: 11} & 1.29 & n.s. \\
\hline
\end{tabular}

n.s.: $p$ value is not significant $(p>0.05)$

\section{Correlations of the Variables Used in the Study}

The scores of the EPDS decreased over the course of time (one-way of analysis of variance, $F=15.4, p<0.001$ ). The scores of the total PBQ increased slightly from 5 days to 1 month after the childbirth $(t=2.2, p<0.05)$ (Table 2).

Table 2. Changes of the scores of EPDS and PBQ (Mean (SE), and the results of repeated ANOVA or paired $t$-test).

\begin{tabular}{|l|l|l|l|l|l|}
\hline & Late pregnancy & 5 days after childbirth & 1 month after childbirth & F or $\boldsymbol{p}$ & $\boldsymbol{p}$ \\
\hline EPDS & $4.40(0.29)$ & $3.74(0.26)$ & $2.96(0.21)$ & $15.44^{\text {a) }}$ & $<.001$ \\
\hline PBQ & - & $11.26(0.57)$ & $12.19(0.60)$ & $2.17^{\text {b) }}$ & 0.03 \\
\hline
\end{tabular}

a): $F$ value, b): $t$ value

SE: Standard Error.

Emotional abuse at 1 month after childbirth was correlated significantly with depression as well as all three PBQ subscales at both 5 days and 1 month after childbirth (Table 3). As expected, depression scores at the three observation points were significantly correlated with each other. Similarly, there was significant correlation between the bonding scores (MAAS and PBQ) at all three time points. The women's initial negative response towards the pregnancy was linked to all the depression and bonding scores at all three observation points, but not to emotional abuse at 1 month after childbirth.

\section{SEM Analysis}

Our final model showed acceptable fit to the data: $\mathrm{CMIN} / d f=2.16, \mathrm{CFI}=0.956$, and RMSEA $=0.069$ (Fig. 1). As expected, depression and bonding scores were correlated throughout the three waves. Error variables between depression and bonding were significantly correlated at both 5 days and 1 month after childbirth. However, depression at one time point did not significantly predict bonding scores at the next time point, nor did bonding predict depression scores. Women's negative response to their pregnancies predicted foetal bonding and depression at 5 days after childbirth $(p<0.01, p<0.05$, respectively). Both depression and bonding scores were predicted by the scores of the previous time points $(p<0.01)$. Finally, bonding failure but not depression at 5 days after childbirth predicted emotionally abusive parenting at 1 month after childbirth $(p<0.05)$. The standardized total effect of the maternal response to the pregnancy on the emotional abuse was 0.05 . 
Table 3. Correlations of all variables and their means and SEs.

\begin{tabular}{|c|c|c|c|c|c|c|c|c|c|c|c|c|c|}
\hline & 1 & 2 & 3 & 4 & 5 & 6 & 7 & 8 & 9 & 10 & 11 & 12 & 13 \\
\hline 1. Emotional abuse & - & & & & & & & & & & & & \\
\hline 2. Depression; pregnancy & .10 & - & & & & & & & & & & & \\
\hline 3. Depression; day 5 & $.16^{*}$ & $.44 * *$ & - & & & & & & & & & & \\
\hline 4. Depression; 1 month & $.29 * *$ & $.43 * *$ & $.61 * *$ & - & & & & & & & & & \\
\hline 5. Foetus bonding & $-.24 * *$ & $-.18^{* *}$ & $-.16^{*}$ & $-.20 * *$ & - & & & & & & & & \\
\hline 6. LA day 5 & $.20 * *$ & .04 & $.18 * *$ & $13^{*}$ & $-.36 * *$ & - & & & & & & & \\
\hline 7. RF day 5 & $.31 * *$ & $.14 *$ & $.37 * *$ & $.21 * *$ & $-.30 * *$ & $40 * *$ & - & & & & & & \\
\hline 8. AR day 5 & $.27 * *$ & $.14 *$ & $.57 * *$ & $.38^{* *}$ & $-.34 * *$ & $.42 * *$ & $.59 * *$ & - & & & & & \\
\hline 9. LA month 1 & $.25 * *$ & .10 & $.20 * *$ & $.24 * *$ & $-.38 * *$ & $61 * *$ & $.31 * *$ & $.36 * *$ & - & & & & \\
\hline 10. RF month 1 & $.29 * *$ & $.22 * *$ & $.45 * *$ & $.35 * *$ & $-.25 * *$ & $26 * *$ & $.49^{* * *}$ & $.45 * *$ & $.39^{* * *}$ & - & & & \\
\hline 11. AR month 1 & $.46 * *$ & $.22 * *$ & $.50 * *$ & $.48 * *$ & $-.38 * *$ & $.35 * *$ & $.43 * *$ & $.72 * *$ & $.37 * *$ & $.54 * *$ & - & & \\
\hline 12. age & .01 & -.05 & \begin{tabular}{|l|l|}
-.01 \\
\end{tabular} & -.08 & .03 & $.15^{*}$ & -.02 & .01 & .10 & .04 & .03 & - & \\
\hline 13. Own response to pregnancy & .11 & $.16^{*}$ & $.20 * *$ & $.15^{*}$ & $-.35 * *$ & $20 * *$ & $.22 * *$ & $.23 * *$ & $.16^{*}$ & $.22 * *$ & $.16^{*}$ & -.03 & - \\
\hline Mean & 8.01 & 4.40 & 3.74 & 2.96 & 71.74 & 1.82 & 0.45 & 9.03 & 1.75 & 0.44 & 9.98 & 30.19 & 1.26 \\
\hline$S E$ & 0.14 & 0.29 & 0.26 & 0.21 & 0.50 & 0.20 & 0.08 & 0.41 & 0.20 & 0.08 & 0.44 & 0.3 & 0.03 \\
\hline
\end{tabular}

\section{DISCUSSION}

A main finding of this study was that emotionally abusive parenting 1 month after childbirth was predicted by bonding disorder but not depressive symptoms at 5 days after childbirth. In accordance with previous investigations, a bivariate correlation matrix showed that emotional abuse and depression were significantly correlated with each other. However, our SEM revealed that this link was spurious.

These findings have public policy implications. In Japan, "Sukoyaka Oyako 21 [Healthy Parents and Children 21]", an early $21^{\text {st }}$ century national plan for the health of mothers and children, has as its goals the healthy development of children and a reduction of parental child-raising anxiety. This policy dictates that local governments should dispatch home visitors to each mother of a newborn baby (Whole Infant Family Visit) to provide physical as well as psychological support to the dyad. It has been recommended that the EPDS be used to screen for postnatal depression because the condition is believed to be a risk factor for infant abuse [51, 52]. However, this study showed that depression did not have a direct effect on neonatal emotional abusive parenting. Just focusing on postnatal depression may be insufficient approach in preventing neonatal or child abuse. Hence we propose that in clinical and community settings, more focus should be placed on bonding disorder especially as a risk factor for emotional abusive parenting. Unfortunately, the assessment of maternal bonding and bonding disorder in the community postnatal care system has been scarcely done. In addition to the use of the EPDS, the use of instruments such as the PBQ by health visitors or midwives may be a possibility. Further, we previously showed that mothers with postnatal depression who did not seek medical support scored significantly higher in bonding failure than those who did [53]. The more the government announces the use of depression screening as a means to identify mothers at risk of infant abuse, the less depressed mothers of infants will seek professional help with fear that they may be viewed as a "abusive mother. Therefore, policy makers should be very careful to distinguish between child abuse prevention and promotion of mothers' general mental health. Identification of mother with depression should be clearly separated from identifying mother at risk of child abuse, however, it is of great importance. Care programs for women identified as with bonding disorders are another very important clinical issue [54].

This longitudinal study revealed longitudinal associations between a negative response towards the present pregnancy, depression, and bonding disorder during the perinatal period, and emotional abuse at 1 month after childbirth. We found that both depression and bonding were moderately to strongly predicted by scores at earlier time points. These results mean that depression and bonding disorder occur over the entire course of the perinatal period, not just during the postnatal period, and are consistent with the findings of previous longitudinal studies [36, 55]. Our results also indicate that both depression and bonding disorder during pregnancy are linked to the woman's negative attitude towards her pregnancy when she learnt that she was pregnant, confirming the result of a previous study [36]. This suggests that perinatal health professionals should pay more attention to women's affection and attitudes towards both the pregnancy and the foetus, beginning at the onset of pregnancy. In Japan, almost all women receive periodic medical check-ups during pregnancy, enabling adequate observation by health professionals. When pregnancy is 
initially confirmed, obstetricians, midwives, and nurses have ample opportunity to evaluate and support women's desire for pregnancy and child rearing, including their motivations for raising a child, and to identify any potential ambivalence [56 - 59]. This type of clinical service is not a routine practice in Japan. The pregnant woman's affection towards her foetus is another very important topic that perinatal health professionals should inquire about when providing psychological support to this population. If the above issues are not addressed by health care providers in common clinical settings, many pregnant women may miss the chance to express negative attitudes towards the current pregnancy and foetus.

There was a significant covariance between depressive moods and bonding disorder at both day 5 and 1 month after childbirth. In addition, there were significant covariances between depressive mood, bonding disorder, and abusive parenting at 1 month after childbirth. We speculate that these three variables often coexist. Our SEM analysis, however, revealed that depressive mood and bonding disorder were causally independent. This analysis suggests the presence of confounders that explain the coexistence of depression, bonding disorder, and abusive parenting. Such unidentified confounding factors were not evaluated in this study, however, and should be identified in future research. They may include the women's experience of being reared by their own parents when they were children, attitudes towards fertility, and personality, to list just a few.

One of the strengths of this study is its longitudinal design, which enabled us to disentangle causal links between variables. When studies are cross-sectional, the results are correlational and thus determining causality is almost impossible.

Nevertheless, our investigation was not free from drawbacks. Our model could explain only about $5 \%$ of the variance in abusive parenting. We failed to identify the third "culprit" factor (other than women's negative attitudes towards the pregnancy) that explains the correlation between depression, bonding failure, and abusive parenting. There may be important factors that were not included in this study. Future investigations should include a greater variety of information, such as the women's personality traits, psychopathology, substance abuse, histories of abuse, characteristics of relationships with significant others, socioeconomic problems, and the support of intimate partners.

In this study, we focused only on neonatal emotional abuse. The very restricted children's age range may require that caution be exercised when interpreting the results. The results of this study cannot be said to relate to any period outside of the neonatal period or to any kind of abuse outside of emotional abuse as assessed with the CTS. The relationship between maternal bonding difficulties and abusive parenting may differ in children of different age ranges.

Another major limitation of this study is the questionable validity of self-report of maternal abusive behavior in this population. Future studies should incorporate information gathered from the other resources such as spouses and family members and child protection agencies. Another weakness of the present study is lack of validation of scales used in the study such as the MAAS.

Taking these drawbacks into consideration, the present study provides preliminary evidence that $5 \%$ of variance of emotionally abusive parenting in the postnatal period was predicted by bonding disorder during the early days after childbirth. Perinatal depression failed to predict neonatal abuse at 1 month after childbirth. Women's negative attitudes towards the present pregnancy are likely to increase the risk of emotionally abusive parenting via bonding failure.

\section{CONCLUSION}

Bonding failure may be a risk factor for neonatal emotional abuse. Negative feelings about the current pregnancy are another risk factor for parenting after birth, via bonding failure. We should pay more attention to women's prenatal attitudes towards their pregnancy and foetus, a practice that is not routinely performed in Japan.

\section{CONFLICT OF INTEREST}

The authors confirm that this article content has no conflict of interest.

\section{ACKNOWLEDGEMENTS}

We thank cooperation of the following clinics. Fukuda Hospital; Suenaga Ob/Gyn Clinic; Jikei Hospital, Kumamoto City Hospital; Kumamoto University Hospital; Kurokawa Gynecologic and Obstetric Clinic; Tashiro Gynecologic and Obstetric Clinic; Amakusa Central General Hospital; Arao Municipal Hospital; Shimokawa Gynecologic and Obsteric Clinic; Kamiamakusa General Hospital; Kataoka Ladies Clinic; Honda Ladies Clinic; Aikoh Obstetrics, Gynecology, and Dermatology Clinic; Yamaguchi Maternity Clinic; Matsubase Ladies Clinic; Kikuyou Ladies Clinic; and Asahino 


\section{General Hospital.}

We are grateful for Dr. H. Kaneko for generously providing the Japanese version of the Postnatal Bonding Questionnaire (PBQ).

\section{REFERENCES}

[1] Norman RE, Byambaa MDeR, Butchart A, Scott J, Vos T. The long-term health consequence of child physical abuse, emotional abuse, and neglect: A systematic review and meta-analysis. PLoS Med 2012; 9: e1001349. [http://dx.doi.org/10.1371/journal.pmed.1001349] [PMID: 23209385]

[2] Brodowski M, Nolan CM, Gaudiosi JA, et al. Nonfatal maltreatment of infants: United States, October, 2005 - September 2006. Mortal Morbidity Wkly Rep 2008; 57: 536-339.

[3] Peltonen K, Ellonen N, Pösö T, Lucas S. Mothers self-reported violence toward their children: a multifaceted risk analysis. Child Abuse Negl 2014; 38(12): 1923-33. [http://dx.doi.org/10.1016/j.chiabu.2014.10.016] [PMID: 25459986]

[4] Ishii Y, Maruyarna A, Anme T, McCall ME. Maternal stress, parenting factors, experiences in day care, and developmental outcomes in 5year-old children in day care in Japan. Jpn J Hum Sci Health-Social Serv 2011; 18: 148-59.

[5] Baydar N. Consequences for children of their birth planning status. Fam Plann Perspect 1995; 27(6): 228-234, 245. [http://dx.doi.org/10.2307/2136174] [PMID: 8666086]

[6] Barber JS, Axinn WG, Thornton A. Unwanted childbearing, health, and mother-child relationships. J Health Soc Behav 1999; 40(3): 231-57. [http://dx.doi.org/10.2307/2676350] [PMID: 10513146]

[7] Brockington I. Maternal rejection of the young child: present status of the clinical syndrome. Psychopathology 2011; 44(5): $329-36$. [http://dx.doi.org/10.1159/000325058] [PMID: 21734436]

[8] De Bellis MD, Broussard ER, Herring DJ, Wexler S, Moritz G, Benitez JG. Psychiatric co-morbidity in caregivers and children involved in maltreatment: a pilot research study with policy implications. Child Abuse Negl 2001; 25(7): 923-44. [http://dx.doi.org/10.1016/S0145-2134(01)00247-2] [PMID: 11523869]

[9] Shay NL, Knutson JF. Maternal depression and trait anger as risk factors for escalated physical discipline. Child Maltreat 2008; 13(1): 39-49. [http://dx.doi.org/10.1177/1077559507310611] [PMID: 18174347]

[10] Walsh C, MacMillan H, Jamieson E. The relationship between parental psychiatric disorder and child physical and sexual abuse: findings from the Ontario Health Supplement. Child Abuse Negl 2002; 26(1): 11-22. [http://dx.doi.org/10.1016/S0145-2134(01)00308-8] [PMID: 11860159]

[11] Smith CL, Spinrad TL, Eisenberg N, Gaertner BM, Popp TK, Maxon E. Maternal personality: Longitudinal Associations to parenting behavior and maternal emotional expressions toward toddlers. Parent Sci Pract 2007; 7(3): 305-29. [http://dx.doi.org/10.1080/15295190701498710] [PMID: 18174914]

[12] Laulik S, Chou S, Browne KD, Allam J. The link between personality disorder and parenting behaviors: A systematic review. Aggress Violent Behav 2013; 18: 644-55.

[http://dx.doi.org/10.1016/j.avb.2013.07.017]

[13] Brennan PA, Le Brocque R, Hammen C. Maternal depression, parent-child relationships, and resilient outcomes in adolescence. J Am Acad Child Adolesc Psychiatry 2003; 42(12): 1469-77. [http://dx.doi.org/10.1097/00004583-200312000-00014] [PMID: 14627882]

[14] Downey G, Coyne JC. Children of depressed parents: an integrative review. Psychol Bull 1990; 108(1): 50-76. [http://dx.doi.org/10.1037/0033-2909.108.1.50] [PMID: 2200073]

[15] Fleming AS, Ruble DN, Flett GL, Shaul DL. Postpartum adjustment in first-time mothers: Relations between mood, maternal attitudes, and mother-infant interactions. Dev Psychol 1988; 24: 71-81. [http://dx.doi.org/10.1037/0012-1649.24.1.71]

[16] Forehand R, Thigpen JC, Parent J, Hardcastle EJ, Bettis A, Compas BE. The role of parent depressive symptoms in positive and negative parenting in a preventive intervention. J Fam Psychol 2012; 26(4): 532-41. [http://dx.doi.org/10.1037/a0028406] [PMID: 22612463]

[17] Leiferman JA, Ollendick TH, Kunkel D, Christie IC. Mothers mental distress and parenting practices with infants and toddlers. Arch Women Ment Health 2005; 8(4): 243-7. [http://dx.doi.org/10.1007/s00737-005-0098-4] [PMID: 16133784]

[18] McLearn KT, Minkovitz CS, Strobino DM, Marks E, Hou W. Maternal depressive symptoms at 2 to 4 months post partum and early parenting practices. Arch Pediatr Adolesc Med 2006; 160(3): 279-84. [http://dx.doi.org/10.1001/archpedi.160.3.279] [PMID: 16520447]

[19] Middleton M, Scott SL, Renk K. Parental depression, parenting behaviours, and behaviour problems in young children. Infant Child Dev 2009; 18: 323-36.

[http://dx.doi.org/10.1002/icd.598] 
[20] Miller L, Kramer R, Warner V, Wickramaratne P, Weissman M. Intergenerational transmission of parental bonding among women. J Am Acad Child Adolesc Psychiatry 1997; 36(8): 1134-9. [http://dx.doi.org/10.1097/00004583-199708000-00022] [PMID: 9256594]

[21] Moehler E, Brunner R, Wiebel A, Reck C, Resch F. Maternal depressive symptoms in the postnatal period are associated with long-term impairment of mother-child bonding. Arch Women Ment Health 2006; 9(5): 273-8. [http://dx.doi.org/10.1007/s00737-006-0149-5] [PMID: 16937313]

[22] Oyserman D, Mowbray CT, Meares PA, Firminger KB. Parenting among mothers with a serious mental illness. Am J Orthopsychiatry 2000; 70(3): 296-315. [http://dx.doi.org/10.1037/h0087733] [PMID: 10953777]

[23] Paulson JF, Dauber S, Leiferman JA. Individual and combined effects of postpartum depression in mothers and fathers on parenting behavior. Pediatrics 2006; 118(2): 659-68. [http://dx.doi.org/10.1542/peds.2005-2948] [PMID: 16882821]

[24] Siomons RL, Lorenz FO, Wu CI, Conger RD. Social network and marital support as mediators and moderators of the impact of stress and depression on parental behavior. Dev Psychol 1993; 29: 368-81. [http://dx.doi.org/10.1037/0012-1649.29.2.368]

[25] Susman EJ, Trickett PK, Iannotti RJ, Hollenbeck BE, Zahn-Waxler C. Child-rearing patterns in depressed, abusive, and normal mothers. Am J Orthopsychiatry 1985; 55(2): 237-51. [http://dx.doi.org/10.1111/j.1939-0025.1985.tb03438.x] [PMID: 3993753]

[26] Takei T, Yamashita H, Yoshida K. The mental health of mothers of physical abused children: The relationship with children's behavioural problems: Report from Japan. Child Abuse Rev 2006; 15: 204-18. [http://dx.doi.org/10.1002/car.936]

[27] Zajicek-Farber ML. Postnatal depression and infant health practices among high-risk women. J Child Fam Stud 2009; 18 : $236-45$. [http://dx.doi.org/10.1007/s10826-008-9224-z]

[28] Windham AM, Rosenberg L, Fuddy L, McFarlane E, Sia C, Duggan AK. Risk of mother-reported child abuse in the first 3 years of life. Child Abuse Neg1 2004; 28(6): 645-67. [http://dx.doi.org/10.1016/j.chiabu.2004.01.003] [PMID: 15193853]

[29] Brockington I. Diagnosis and management of post-partum disorders: a review. World Psychiatry 2004; 3(2): 89-95. [PMID: 16633463]

[30] Brockington IF, Aucamp HM, Fraser C. Severe disorders of the mother-infant relationship: definitions and frequency. Arch Women Ment Health 2006; 9(5): 243-51.

[http://dx.doi.org/10.1007/s00737-006-0133-0] [PMID: 16699838]

[31] Kumar RC. Anybodys child: severe disorders of mother-to-infant bonding. Br J Psychiatry 1997; 171: $175-81$. [http://dx.doi.org/10.1192/bjp.171.2.175] [PMID: 9337956]

[32] Brockington IF. Motherhood and mental Health. Oxford: Oxford University Press 1996; pp. 327-66.

[33] Kitamura T, Takegata M, Haruna M, et al. The Mother-Infant Bonding Scale: Factor structure and psychosocial correlates of parental bonding disorders in Japan. J Child Fam Stud 2015; 24: 393-401. [http://dx.doi.org/10.1007/s10826-013-9849-4]

[34] Kitamura T, Ohashi Y, Kita S, Haruna M, Kubo R. Depressive mood, bonding failure, and abusive parenting among mothers with threemonth-old babies in a Japanese community. Open J Psychiatr 2013; 3: 1-7. [http://dx.doi.org/10.4236/ojpsych.2013.33A001]

[35] Mercier RJ, Garrett J, Thorp J, Siega-Riz AM. Pregnancy intention and postpartum depression: secondary data analysis from a prospective cohort. BJOG 2013; 120(9): 1116-22.

[http://dx.doi.org/10.1111/1471-0528.12255] [PMID: 23651010]

[36] Kokubu M, Okano T, Sugiyama T. Postnatal depression, maternal bonding failure, and negative attitudes towards pregnancy: a longitudinal study of pregnant women in Japan. Arch Women Ment Health 2012; 15(3): 211-6. [http://dx.doi.org/10.1007/s00737-012-0279-x] [PMID: 22526407]

[37] Straus MA, Hamby SL. Measuring physical and psychological maltreatment of children with the Conflict Tactics Scales Manual for the conflict tactics scales (CTS) and test forms for the revised conflict tactics scales. Durham, NH: University of New Hampshire, M. A. Straus. Family Research Laboratory 1995.

[38] Cox JL, Holden JM, Sagovsky R. Detection of postnatal depression. Development of the 10-item Edinburgh Postnatal Depression Scale. Br J Psychiatry 1987; 150: 782-6. [http://dx.doi.org/10.1192/bjp.150.6.782] [PMID: 3651732]

[39] Okano T, Masuji F, Tamaki R, et al. Nihonban Edinburgh sango utu-byo jikohyoukahyou (EPDS) no sinraisei to datousei. Arch Psychiatr Diagn Clin Eval 1996; 7: 525-33. [Validation and reliability of Japanese version of the Edinburgh Postnatal Depression Scale (EPDS)]. [in Japanese].

[40] Condon JT. The assessment of antenatal emotional attachment: development of a questionnaire instrument. Br J Med Psychol 1993; 66(Pt 2): $167-83$. 
[http://dx.doi.org/10.1111/j.2044-8341.1993.tb01739.x] [PMID: 8353110]

[41] Kaneko H. Early intervention and support system for postpartum depression and postpartum bonding disorders (Report No. 21730547). Tokyo, Japan. Grants-in aid for scientific research by the Ministry of Education, Culture, Sports, Science, and Technology in Japan 2011. (in Japanese)

[42] Brockington IF, Fraser C, Wilson D. The postpartum bonding questionnaire: a validation. Arch Women Ment Health 2006 ; 9(5): 233-42. [http://dx.doi.org/10.1007/s00737-006-0132-1] [PMID: 16673041]

[43] Brockington IF, Oats J, George S, et al. A screening questionnaire for mother-infant bonding disorders. Arch Women Ment Health 2001; 3: $133-40$

[http://dx.doi.org/10.1007/s007370170010]

[44] Kaneko H, Honjo S. The psychometric properties and factor structure of the Postpartum Bonding Questionnaire in Japanese mothers. Psychology 2014; 5: 1135-42. [http://dx.doi.org/10.4236/psych.2014.59126]

[45] Suetsugu Y, Honjo S, Ikeda M, Kamibeppu K. The japanese version of the postpartum bonding questionnaire: examination of the reliability, validity, and scale structure. J Psychosom Res 2015; 79(1): 55-61. [http://dx.doi.org/10.1016/j.jpsychores.2015.02.008] [PMID: 25818345]

[46] Ohashi Y, Kitamura T, Sakanashi K, Tanaka T. Postpartum bonding disorder: factor structure, validity, reliability and a model comparison of the postnatal bonding questionnaire in japanese mothers of infants. Healthcare (Basel) 2016; 4(3): 50. [http://dx.doi.org/10.3390/healthcare4030050] [PMID: 27490583]

[47] Arbuckle JL, Wothke W. Amos 4.0 User's Guide. Small Waters Corporation. 1985-1999.

[48] Klein RB. Principles and practice of structural equation modeling. $2^{\text {nd }}$ ed. New York: Guilford 2005

[49] Schermelleh-Engell K, Moosbrugger H, Müller H. Evaluating the fit of structural equation models: tests of significance and descriptive goodnesss-of-fit measures. Methods Psychol Res Online 2003; 8(2): 23-74.

[50] Ministry of Health, Labour and Welfare. Annual Health, Labour and Welfare Report 2012-2013 (Summary). Tokyo, Japan, 2013. [Retrieved 2016 June 15] Available from: http://www.mhlw.go.jp/english/wp/wp-hw7/dl/summary.pdf (in Japanese)

[51] Ministry of Health Lobour and welfare. Sukoyaka Oyako 21 dai 2 kai tyukan hyouka torimatome ni tuite [The 2nd interim evaluation report of Sukoyaka Oyako 21 Plan. Tokyo, Japan. Available from: http://www.mhlw.go.jp/shingi/2010/02/dl/s0205-13a.pdf 2009.

[52] Ministry of Health Lobour and welfare. Nyu-youji zenko houmon guidline [The guideline of the Whole Visits for infants-toddler]. Tokyo, Japan 2015. Available from: http://www.mhlw.go.jp/bunya/kodomo/kosodate12/03.html

[53] Kitamura T, Yamashita H, Yoshida K. Seeking medical support for depression after the childbirth: A Study of Japanese community mothers of 3-month-old babies. Open Wom Health J 2009; 3: 1-14. [http://dx.doi.org/10.2174/1874291200903010001]

[54] McGregor J, Casey J. Enhancing parent-infant bonding using kangaroo care: A structured review. Evidence Based Midwifery 2012; 10: 50-6.

[55] Yoshida K, Yamashita H, Conroy S, Marks M, Kumar C. A Japanese version of Mother-to-Infant Bonding Scale: factor structure, longitudinal changes and links with maternal mood during the early postnatal period in Japanese mothers. Arch Women Ment Health 2012; 15(5): 343-52. [http://dx.doi.org/10.1007/s00737-012-0291-1] [PMID: 22733162]

[56] Brückner H, Martin A, Bearman PS. Ambivalence and pregnancy: adolescents attitudes, contraceptive use and pregnancy. Perspect Sex Reprod Health 2004; 36(6): 248-57.

[http://dx.doi.org/10.1363/3624804] [PMID: 15687083]

[57] Cowley C, Farley T. Adolescent girls attitudes toward pregnancy: the importance of asking what the boyfriend wants. J Fam Pract 2001; 50(7): 603-7. [PMID: 11485709]

[58] Groat HT, Giordano PC, Cernkovich SA, Pugh MD. Attitudes toward childbearing among young parents. J Marriage Fam 1997; 59: 568-81. [http://dx.doi.org/10.2307/353946]

[59] Söderberg M, Lundgren I, Christensson K, Hildingsson I. Attitudes toward fertility and childbearing scale: an assessment of a new instrument for women who are not yet mothers in Sweden. BMC Pregnancy Childbirth 2013; 13: 197. [http://dx.doi.org/10.1186/1471-2393-13-197] [PMID: 24165014]

(C) Ohashi et al; Licensee Bentham Open

This is an open access article licensed under the terms of the Creative Commons Attribution-Non-Commercial 4.0 International Public License (CC BY-NC 4.0) (https://creativecommons.org/licenses/by-nc/4.0/legalcode), which permits unrestricted, non-commercial use, distribution and reproduction in any medium, provided the work is properly cited. 